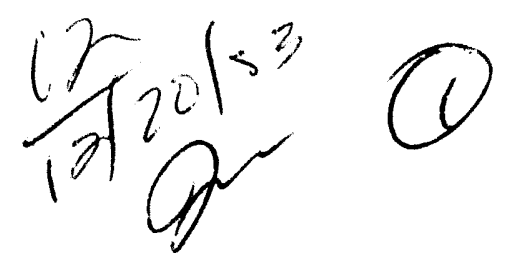

\title{
Computer Simulations of WIGWAM Underwater Experiment
}

\author{
Minao Kamegai and John W. White
}

November 1993

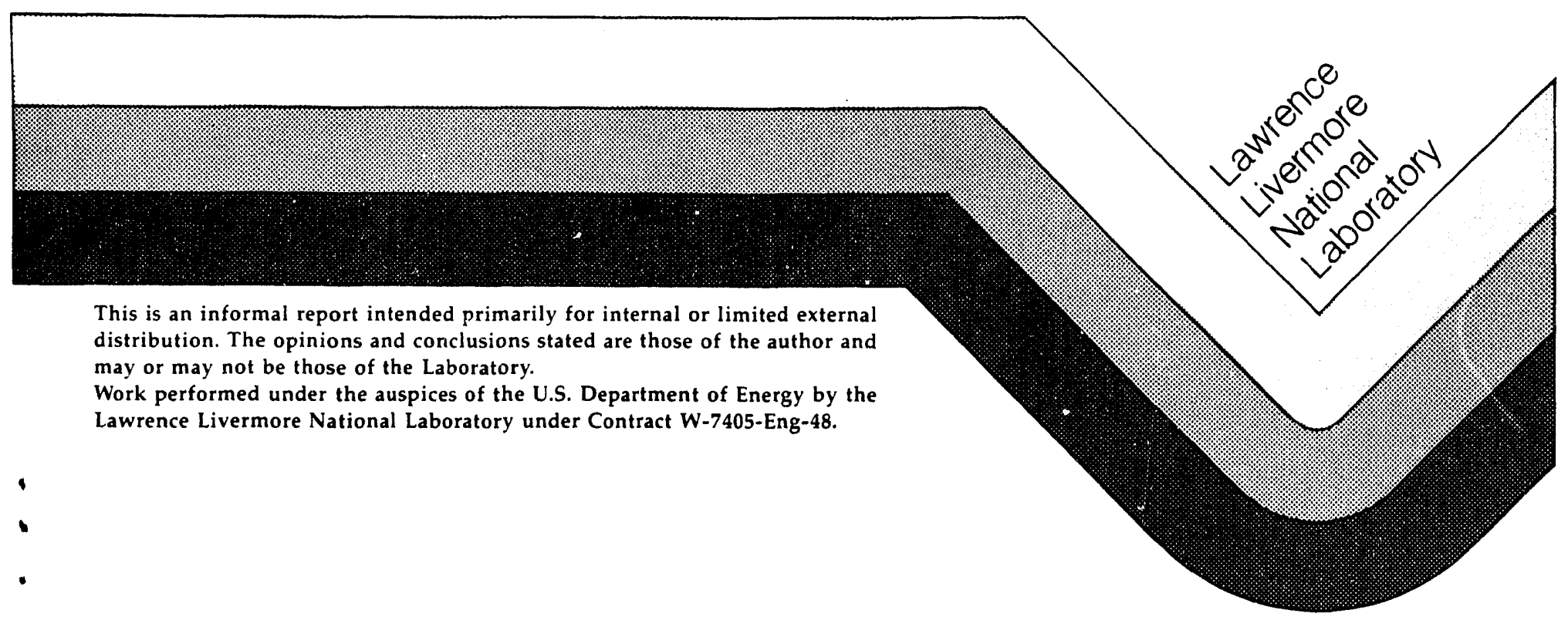




\section{DISCLAIMER}

This document was prepared as an account of work sponsored by an agency of the United States Government. Neither the United States Government nor the University of California nor any of their employees, makes any warranty, express or implied, or assumes any legal liability or responsibility for the accuracy, completeness, or usefulness of any information, apparatus, product, or process disclosed, or represents that its use would not infringe privately owned rights. Reference herein to any specific commercial products, process, or service by trade name, trademark, manufacturer, or otherwise, does not necessarily constitute or imply its endorsement, recommendation, or favoring by the United States Government or the University of California. The views and opinions of authors expressed herein do not necessarily state or reflect those of the United States Government or the University of California, and shall not be used for advertising or product endorsement purposes.

This report has been reproduced directly from the best available copy.

Available to DOE and DOE contractors from the Office of Scientific and Technical Information

P.O. Box 62, Oak Ridge, TN 37831

Prices available from (615) 576-8401, FTS 626-8401

Available to the public from the

National Technical Information Service

US. Department of Commerce

5285 Port Royal Rd.

Springfield, VA 22161 
Computer Simulations of WIGWAM Underwater Experiment

\author{
Minao Kamegai and John W. White \\ Lawrence Livermore National Laboratory \\ Livermore, CA 94551
}

\begin{abstract}
We performed computer simulations of the WIGWAM underwater experiment with a 2-D hydro-code, CALE. First, we calculated the bubble pulse and the signal strength at the closest gauge in one-dimensional geometry. The calculation shows excellent agreement with the measured data. Next, we made two-dimensional simulations of WIGWAM applying the gravity over-pressure, and calculated the signals at three selected gauge locations where measurements were recorded. The computed peak pressures at those gauge locations come well within the $15 \%$ experimental error bars. The signal at the farthest gauge is of the order of 200 bars. This is significant, because at this pressure the CALE output can be linked to a hydro-acoustics computer program, NPE Code (Nonlinear Progressive Wave-equation Code), to analyze the long distance propagation of acoustical signals from the underwater explosions on a global scale.
\end{abstract}

\title{
Introduction
}

The objective of the WIGWAM simulations is to verify the computational scheme for propagating underwater waves by comparing the computer simulated underwater event against the real underwater experiment. Thereby we establish the credibility for our computer simulation studies of hypothetical underwater (and abovewater) explosions under various conditions.

WIGWAM is a deep water nuclear explosion on which many measurements were taken.1,2 The depth of exp! ssion was $2000 \mathrm{ft}$ in about $15000 \mathrm{ft}$ of water, which eliminated interference from the ocean floor within the measurement time. The objective was to study the characteristics of an underwater shock wave from close-in distance to $2500 \mathrm{ft}$ away. A four year preparation program developed the instrumentation in order to insure the acquisition of data. Redundant measurements were made so that if one system failed, the other would acquire data. Two sets of multichannel telemeter systems were suspended in water at $70 \mathrm{ft}$ from the zero station. Each system had eight gauges located at depths of $25,50,100,200,500,750,1000$ and $1200 \mathrm{ft}$. The third telemeter system was suspended at $2500 \mathrm{ft}$ away from the zero station. In addition to the telemeters, a recording instrument 
using a magnetic-tape recorder was employed at the zero station.

We performed computer simulations of WIGWAM, using a two dimensiunal hydro-code, CALE. ${ }^{3}$ First, we calculated the bubble pulse in onedimensional geometry with a constant gravitational over-pressure in the water. This means that the water was treated as if it were all at the same depth. In choosing the depth, a correction was included to account for the fact that the bubble is rising during the pulse. These calculations will be discussed later in more detail, but for now we note that the calculated first period of the bubble pulse agrees very well with the measurement. Next we made twodimensional simulations of WIGWAM applying the gravity over-pressure so that ambient water pressure varied with depth. In these simulations, we computed the signals at three selected gauge locations (described later) where both telemeter data and magnetic-tape data were successfully recorded. Guided by the scatter in the data, we estimated an error of $15 \%(2 \sigma)$ on the measurements. The computed peak pressures at those gauge locations come well within the $15 \%$ error bars.

The output from the CALE calculation will be linked to NPE Code 4,5 (Nonlinear Progressive Wave-equation Code), which was developed at the Naval Research Laboratory to study ocean acoustics. Ed McDonald of the Naval Research Laboratory estimates that when signal peak pressures fall below one-tenth of the bulk modulus of water $(22.4 \mathrm{kbars})$, the weak shock model of the NPE Code provides fairly accurate answers. However, we ran all the CALE calculations to the point where peak pressures are below onehundredth of the bulk modulus, i.e. below 224 bars, before linking to the NPE Code. This insures that the weak shock model will be accurate. By using the NPE Code, we will analyze the unique characteristics of ocean acoustics resulting from underwater explosions on a global scale. In this report, we will show that the CALE computer program indeed meets these requirements.

\section{WIGWAM Experiment}

The experimental arrangement of WIGWAM is shown in Fig. 1. Floating telemeter stations were placed directly above the work point (zero station) and $2500 \mathrm{ft}$ (satellite station) from the zero station. The gauges were tourmaline piezoelectric pressure pickups which were water-proofed to withstand the over-pressure. Each gauge cable was a single-conductor, shielded, low noise, neoprene-covered cable specifically developed for piezoelectric gauges. The gauges were calibrated and assembled at the Naval Ordinance Laboratory Field Station in Indian Head, Md. Eight gauges were used for each telemeter system along with a magnetic recorder system. There were two telemeter systems and one magnetic recorder system at the zero station and one telemeter system at the satellite station. Figure 2 shows the gauge locations on the cables at the zero station. 
The gauges selected for calculations are from channels 3,5 and 8 in Fig. 2, and they were suspended at the depths of 100,500 and $1200 \mathrm{ft}$, respectively. The slant ranges from the work point to these gauges are, respectively, 580, 458 and 245 meters. The yield of the explosion was measured by three groups, and they reported the following yield magnitudes:

\begin{tabular}{ll} 
LASL & $32 \mathrm{kt}$ \\
NRL & $34 \mathrm{kt}$ \\
ARF & $30.5 \mathrm{kt}$ \\
\hline Average & $32.2 \mathrm{kt}$
\end{tabular}

The first period of the bubble pulse was measured with piezoelectric gauges and Wiancko electromechanical gauges. The average value of all the measurements was $2.88 \mathrm{sec}$. The measurement of bubble migration was approximate, and the estimated value was something less than $400 \mathrm{ft}$ in upward direction.

\section{Computer Simulations}

We applied a two dimensional hydrodynamic computer program, CALE, to simulate the WIGWAM experiment. CALE is an improved version of a LLNL ALE Code6 (Arbitrary Lagrangian Eulerian Program) which was originally developed to solve astrophysical problems. CALE was written in the "C" programming language to give both portability and a high degree of flexibility.

The bubble pulse $v$ as calculated in a one-dimensional wedge with a wedge angle $1.14593^{\circ}$. The wedge angle was chosen so that the volume of a cone generated by the wedge would be precisely $1 / 10000$ of the sphere. The energy source was an iron gas sphere laid over five radial zones with a radius of $2.15 \mathrm{~m}$ and density of $0.1 \mathrm{gm} / \mathrm{cc}$. Outside the iron gas was a column of water with radial zones geometrically increasing from $0.1 \mathrm{~m}$ to $20 \mathrm{~m}$ up to a radius of 400 meters, and constant thickness water zones of $20 \mathrm{~m}$ beyond this radius. We found that this zoning provided numerical convergence in calculating the bubble pulse. Since the first period is nearly $3 \mathrm{sec}$, the wave front travels about $4.5 \mathrm{~km}$ during this time. To accommodate a long distance propagation of the wave, a $3.6 \mathrm{~km}$ water column was sufficient to prevent the return of a rarefaction wave from the outer boundary of the problem to the bubble.

The bubble migration was less than $400 \mathrm{ft}$ in the upward direction during the first period, thus the bubble experienced a reduction of the overpressure from 61 bars to about 50 bars. We took the average pressure, 56 bars, and applied it uniformly in the water column for the calculation of the bubble pulse. For the calculation of signal strength at the wave front, a much finer 
zoning, $0.5 \mathrm{~m}$ for the maximum zone thickness, was used to obtain accurate results.

Two-dimensional simulation of the WIGWAM experiment was made using a polar mesh. A schematic view of the simulation is shown in Fig. 3 . The energy source was modeled by an iron gas bubble with density of 0.1 $\mathrm{gm} / \mathrm{cc}$ and radius $2.15 \mathrm{~m}$. The total mass of the iron bubble was $4163 \mathrm{~kg}$ in which $32 \mathrm{kt}$ of energy was uniformly distributed. This simple energy source modeled on the CALE Code without radiation flow gave the same hydrodynamic history as was obtained by a calculation which accounted for energy production and radiation flow as found in nuclear design computer codes. Therefore, we believe that a model without radiation flow is sufficient to treat this problem.

The iron bubble was placed in the center of a sphere of water which has a density of $1.0035 \mathrm{gm} / \mathrm{cc}$ instead of $1.00 \mathrm{gm} / \mathrm{cc}$. This density adjustment was made to the water so that a correct reading (61 bars) of the gravity overpressure was observed at the work point. The horizontal air-water interface was laid at $609 \mathrm{~m}$ above the iron bubble. The region above the interface was filled with air of density $1.3 \mathrm{e}-3 \mathrm{gm} / \mathrm{cc}$.

The angular resolution of the polar grid was $5^{\circ}$. There were five radial zones in the bubble, and the radial zoning in the ambient water was geometrically increased from a $0.1 \mathrm{~m}$ zone at the gas-water interface to a maximum zone size. We found that the peak pressures at the gauge locations are quite sensitive to the maximum radial zone size. We investigated the zone size effects by computing with three different maximum zone sizes $(2 \mathrm{~m}, 1 \mathrm{~m}$ and $0.5 \mathrm{~m}$ ). For the smallest of these, the solution had converged numerically. H-Division at LLNL developed the equation-of-state for iron, for air and for water; and they are each in a tabular form with a temperature base. The gravitational over-pressure was calculated starting from the water surface where the over-pressure is set at one atmosphere.

The goal was to calculate the peak pressures at the three selected gauges. Therefore, the computation was carried out until the farthest gauge registered a signal. The time required for the shock wave to pass the last detector was $500 \mathrm{msec}$.

\section{Results and Discussion}

The 1-D calculation of the bubble pulse took only a few minutes of CPU time. By utilizing a large zone size (maximum $20 \mathrm{~m}$ ), which requires fewer number of zones for a given problem, we expedited the computational process. With the over-pressure of 56 bars uniformly applied in the water column and the density of $1.00252 \mathrm{gm} / \mathrm{cc}$ for water, the calculated first period 
of oscillation was $2.87 \mathrm{sec}$, which is in good agreement with the measured value of $2.88 \mathrm{sec}$. When the over-pressure was varied by $5 \%$, the pulsation period changed only by $2 \%$.

We also made 1-D calculations of the gauge signal at $245 \mathrm{~m}$ from the bubble center ( corresponding to channel 8 gauge), using a finer zoning, $0.5 \mathrm{~m}$ maximum, in the water column. The telemeter reading and the magnetic-tape data on the signal from the channel 8 gauge are, respectively, 580 bars and 544 bars, the average of which comes to 562 bars. With a uniform over-pressure of 61 bars in the water, the calculated peak pressure at $245 \mathrm{~m}$ was 570 bars, which is within $2 \%$ of the measurement. The peak pressure was found to be quite sensitive to the maximum zone size and the linear $Q$ (artificial viscosity). Fine zoning and a small coefficient for the scalar John White $\mathrm{Q}^{7}$ are boih required. Refinement of angular resolution beyond $5^{\circ}$ did not have much effect on the results.

A total of six 2-D problems were calculated: they are WIGWAM simulations by the CALE computer program operating in its ALE mode ("nearly" Lagrangian), using a polar grid with three different maximum zone sizes, $2 \mathrm{~m}, 1 \mathrm{~m}$ and $0.5 \mathrm{~m}$, and then these three calculations were repeated by CALE operating in the pure Eulerian mode. Three "tracer particles" were placed at coordinates, $\mathrm{rz}(\mathrm{m})=(21.34,243.8),(21.34,457.2)$ and $(21.34,579.1)$, which respectively correspond to the locations of the three gauges, channels 8 , 5 and 3 . These particles were independent of the grid or material motion and fixed in space at those rz-coordinates. As the wave passes the particle, the pressure at the particle was monitored and stored away every 100 microseconds. The peak pressures at the particles were then compared with the telemeter and the magnetic recorder data from the gauges, as shown in Fig. 4. Both numerical methods ("nearly" Lagrangian and Eulerian) exhibited convergence properties, but neither had completely converged with fine zoning. However, we observe that in Fig. 4 the Eulerian calculations are in better agreement with the measurements at large ranges (channel 5 gauge and channel 3 gauge). The "nearly" Lagrangian calculation agrees better for the closest gauge (channel 8 gauge).

The farthest gauge ( channel 3 ) at $580 \mathrm{~m}$ was positioned $100 \mathrm{ft}$ below the water surface, and thus the signal was cut off by the surface release wave. The telemeter data from the channel 3 gauge were compared to the calculation in Fig. 5. The agreement we observe in the cut-off time shows that the release wave as well as the shock front is calculated well by CALE. The surface rarefaction wave is known to distort the wave front in a distinct way ${ }^{8}$, and how this will affect the acoustic signal at a great distance from the source is yet to be examined.

Figures 6 and 7 are the snapshots of the bubble at $100 \mathrm{msec}$ and 300 msec, respectively. The original center of the bubble is driven downward and 
oscillates, but the bubble boundary is expanding spherically showing very little upward migration at these early times. The plots of boundary motion taken at the top, the bottom and the equator of the bubble confirm this observation. The Eulerian calculation behaves similarly with respect to the outer boundary of the bubble, but no such oscillation is observed in the Eulerian mode calculations. The oscillation of the bubble center is a mesh artifice, and it does not imply a material oscillation. It has no adverse effect on the calculations.

\section{Concluding Remarks}

The calculated first period of the bubble pulse is in excellent agreement with the measurements. The 1-D calculation of the signal at $245 \mathrm{~m}$ corresponding to the closest gauge, channel 8 gauge, agrees with the measurements within $2 \%$. We also calculated the signals at three selected gauges in 2-D simulations. The farthest gauge registered a peak pressure on the order of 200 bars. The calculated values at this gauge come well within the estimated experimental error bar of $15 \%$.

The CALE computer program meets the requirements for this investigation:

1 - CALE can simulate underwater explosions near the source

2 - CALE can accurately calculate the long distant propagation of an

underwater wave until the peak pressure decays to about 200 bars.

The future plan is as follows:

1 - We will examine the propagation of signals to greater ranges

2 - We will vary the CALE-NPE link time conditions to examine the sensitivity of both codes to their operating regime

3 - We will examine the effect of varying the height or depth of burst

4 - We will compare calculations to hydrophonic data.

These activities will require coupling of the CALE code to the NPE computer program.

\section{Acknowledgment}

The authors wish to thank Lew Glenn, Doug Clarke and Dave Harris for discussions and many helpful suggestions for this work. 


\section{References}

1. Cunningham, C. B., "Operation WIGWAM, Free-field Press'ures, Station Zero," WT-1006, U.S. Naval Research Laboratory, Washington D.C., December 1955

2. Aronson, C. J. et al, "Operation WIGWAM, Underwater Free-field Pressures to Just Beyond Target Locations," Naval Ordinance Laboratory, White Oak, Silver Spring, Maryland, May 1956

3. Tipton, R., CALE Users Manual, Version 920701 Lawrence Livermore National Laboratory, Livermore, CA, July 1, 1992

4. McDonald, B. E. and Kuperman, W. A., "Time-Domain Solution of the Parabolic Equation Including Non-linearity," Comp. and Maths. with Appls. vol 11, pp843-851, Pergamon Press Ltd. 1985, Great Britain

5. Ambrosiano, J. J., Plante, D. R., McDonald, B. E. and Kuperman, W. A., "Nonlinear Propagation in an Ocean Acoustic Waveguide," J. Acoust Soc. Am. vol 87 (4), pp1473-1482, 1990

6. Barton, R. T., "Development of a Multimaterial Two-dimensional, Arbitrary Lagrangian-Eulerian Mesh Computer Program," Numerical Astrophysics, J. M. Centrella, J. M. LeBlanc, R. L. Bowers, eds., Jones and Bartlett Publishers, 1985, Boston

7. White, J. W., "A New Form of Artificial Viscosity: Postscript," Journal of Computational Physics, vol 12, pp553-556, August 1973

8. Kamegai, M., Klein, L. S. and Rosenkilde, C. E., "Computer Simulation Studies on Free Surface Reflection of Underwater Shock Waves," Proceedings of the Sixteenth International Symposium on Shock Tubes and Waves, Aachen, Germany, July 26-31 1987, p351, ed. Hans Gronig, VCH Publishers 1988 


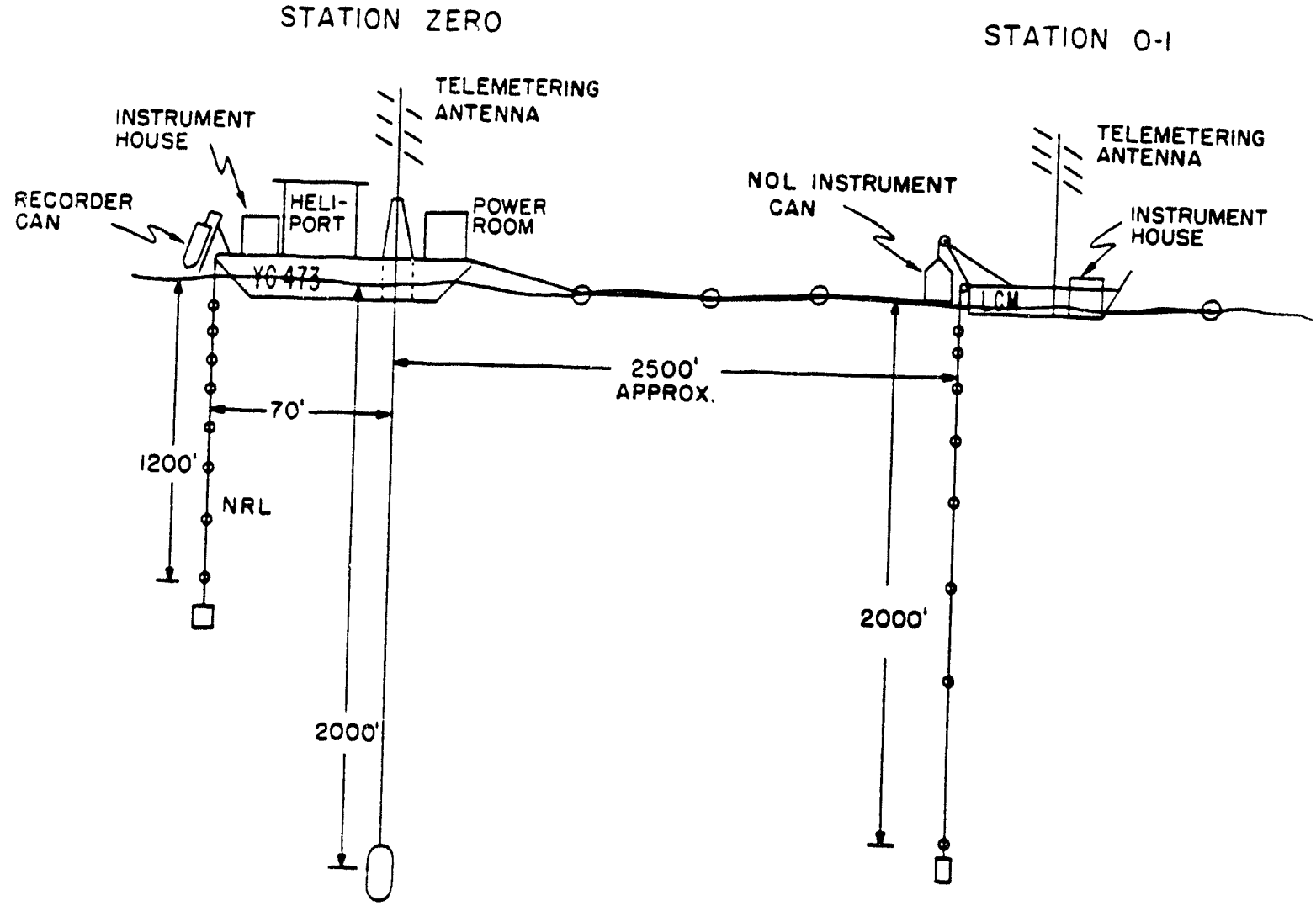

Fig. 1 WIGWAM experimental arrangement The gauge locations are shown at the station zero and the satellite station $0-1$. 


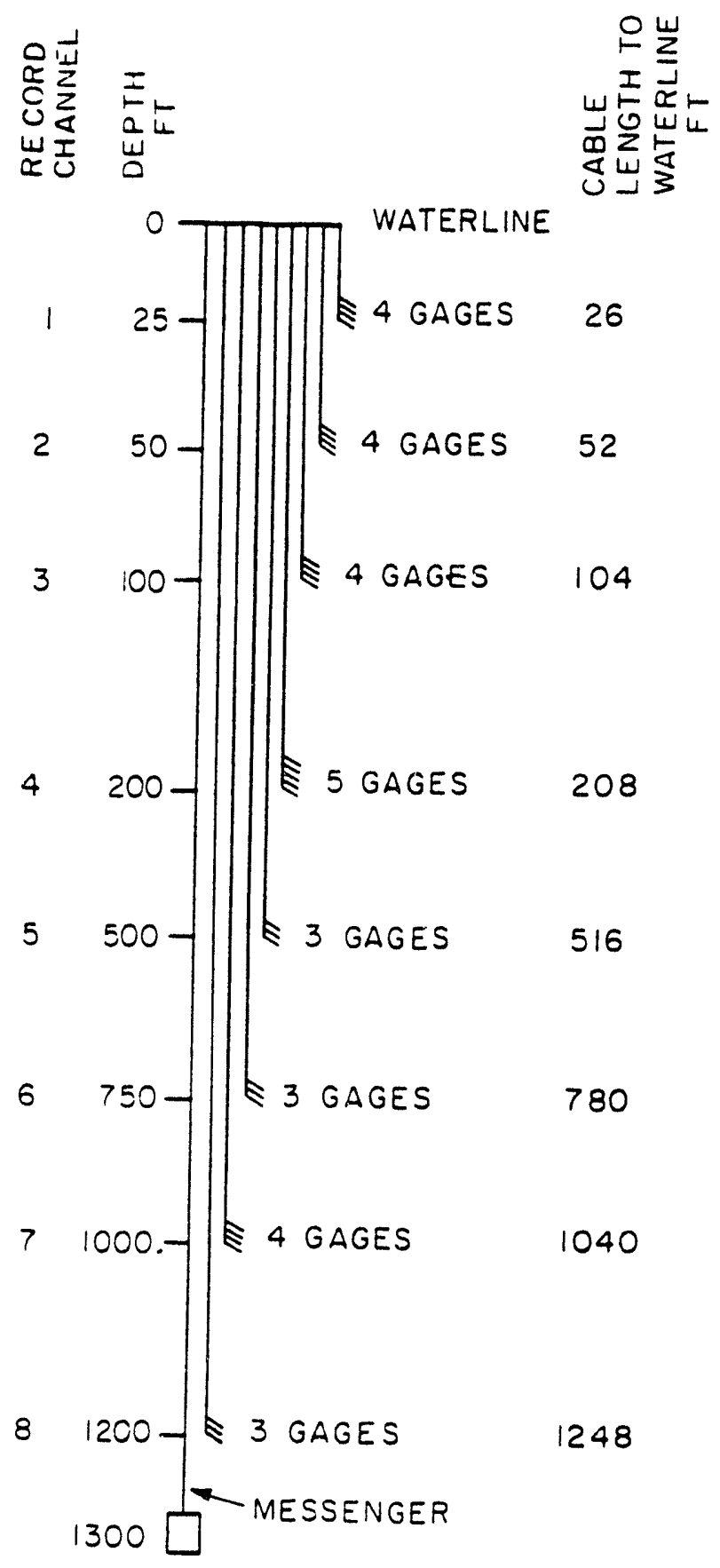

Fig. 2 Gauge cables at the station zero

Eight gauge locations are shown along the cable at the station zero. 


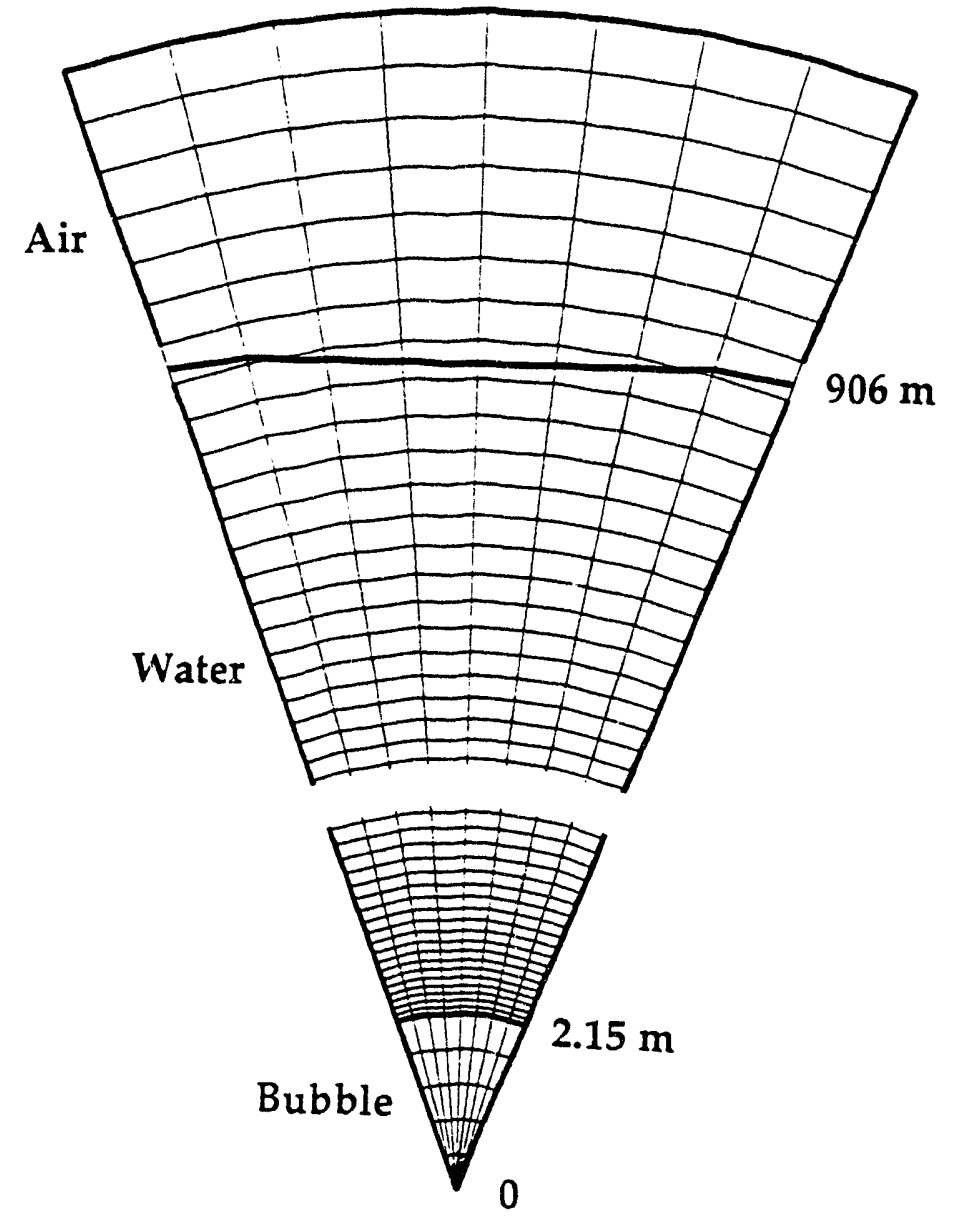

Fig. 3 Schematic view of the WIGWAM simulation in a polar grid
for the 2-D calculations Angular resolution is $5^{\circ}$. There are 5 radial zones in the bubble, and radial zoning in water geometrically increases from $0.1 \mathrm{~m}$ at the gaswater interface to a maximum zone size. The horizontal line at $906 \mathrm{~m}$ above the center indicates the water surface. 


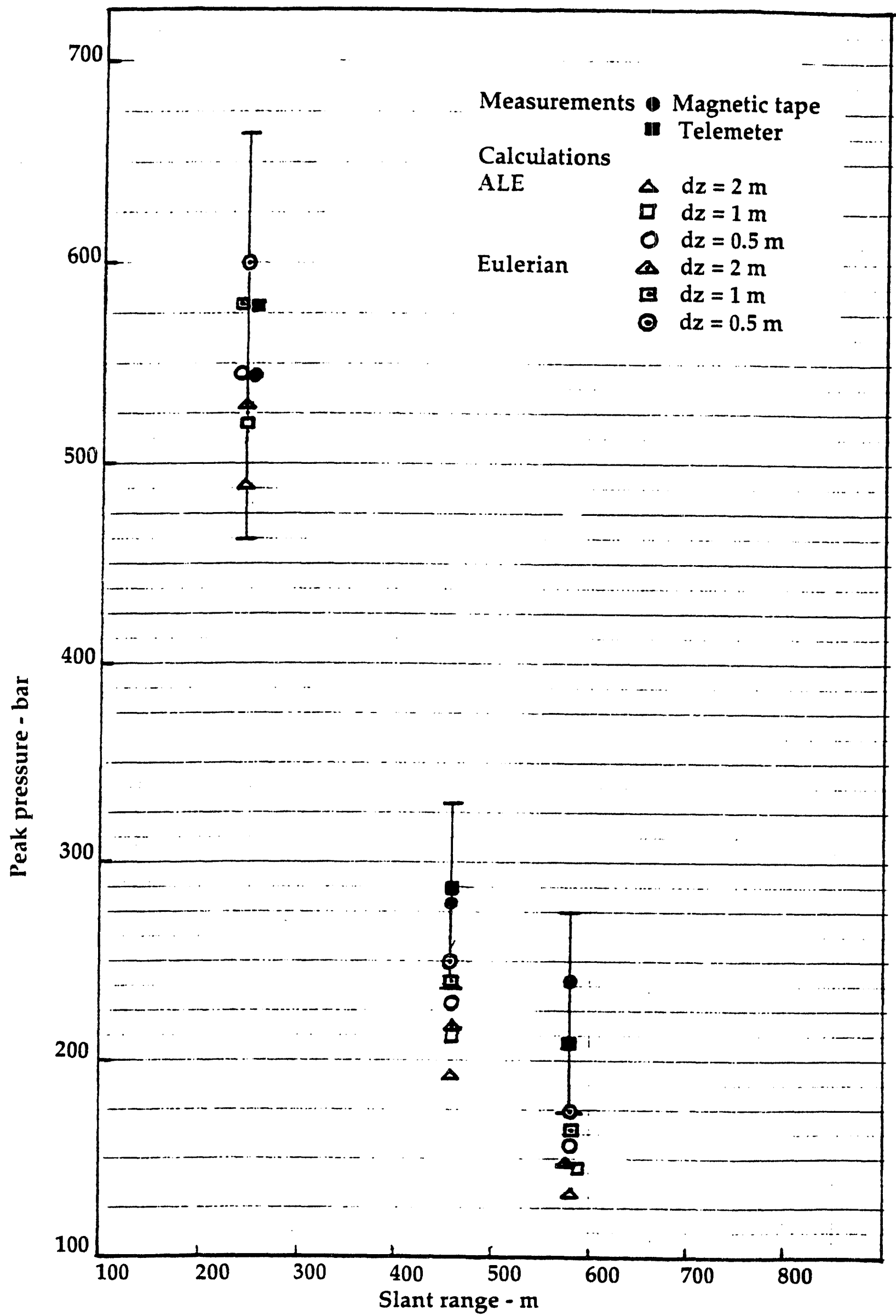

Fig. 4 Peak pressures at three gauge locations, calculations and measurements The three gauges, channels 8,5 and 3 , were located at the slant ranges of 245,458 and $580 \mathrm{~m}$ from the work point, respectively. 


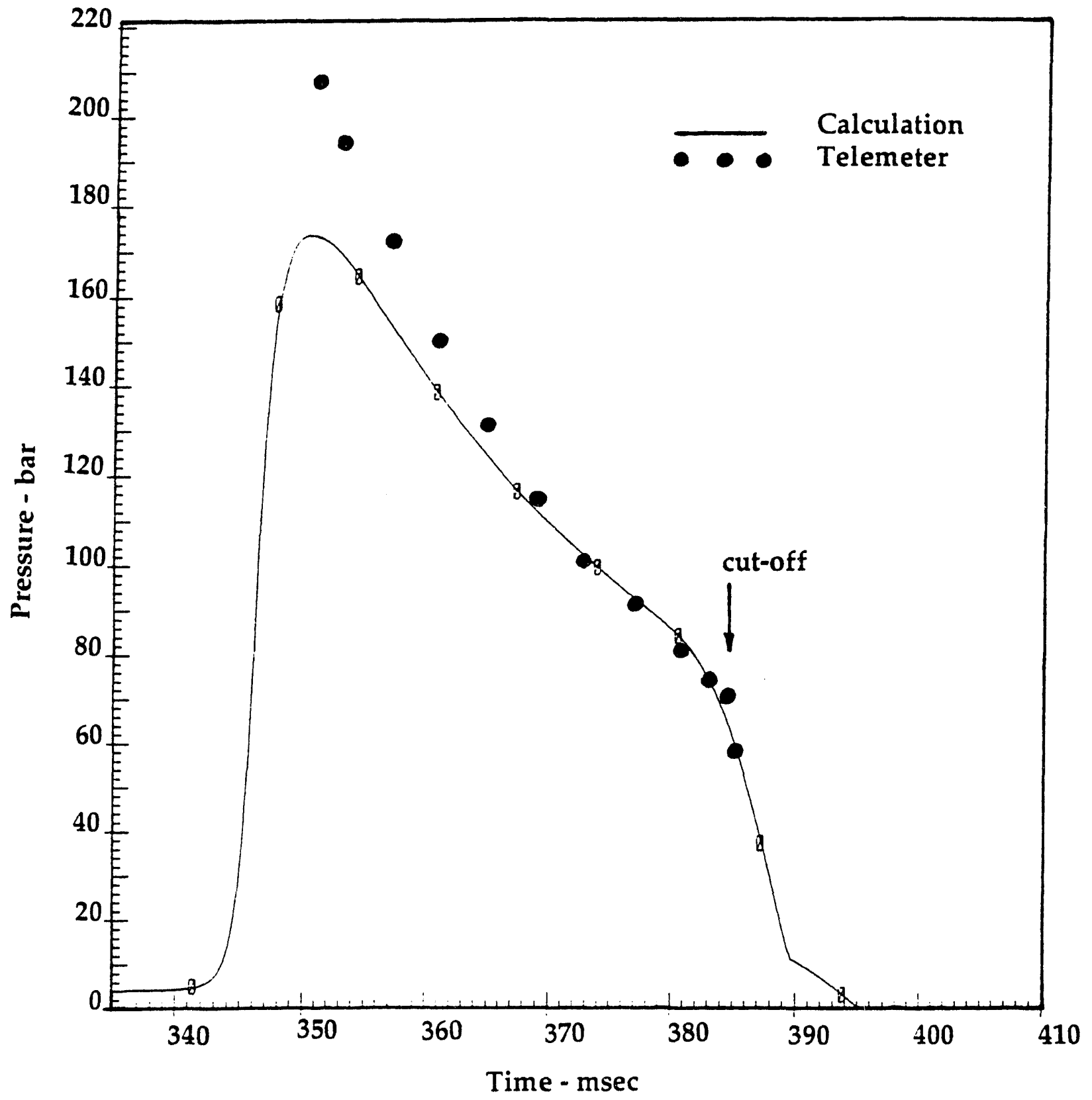

Fig. 5 Channel 3 gauge readings, Eulerian calculation and measurements Cut-off is caused by the surface rarefaction wave. 


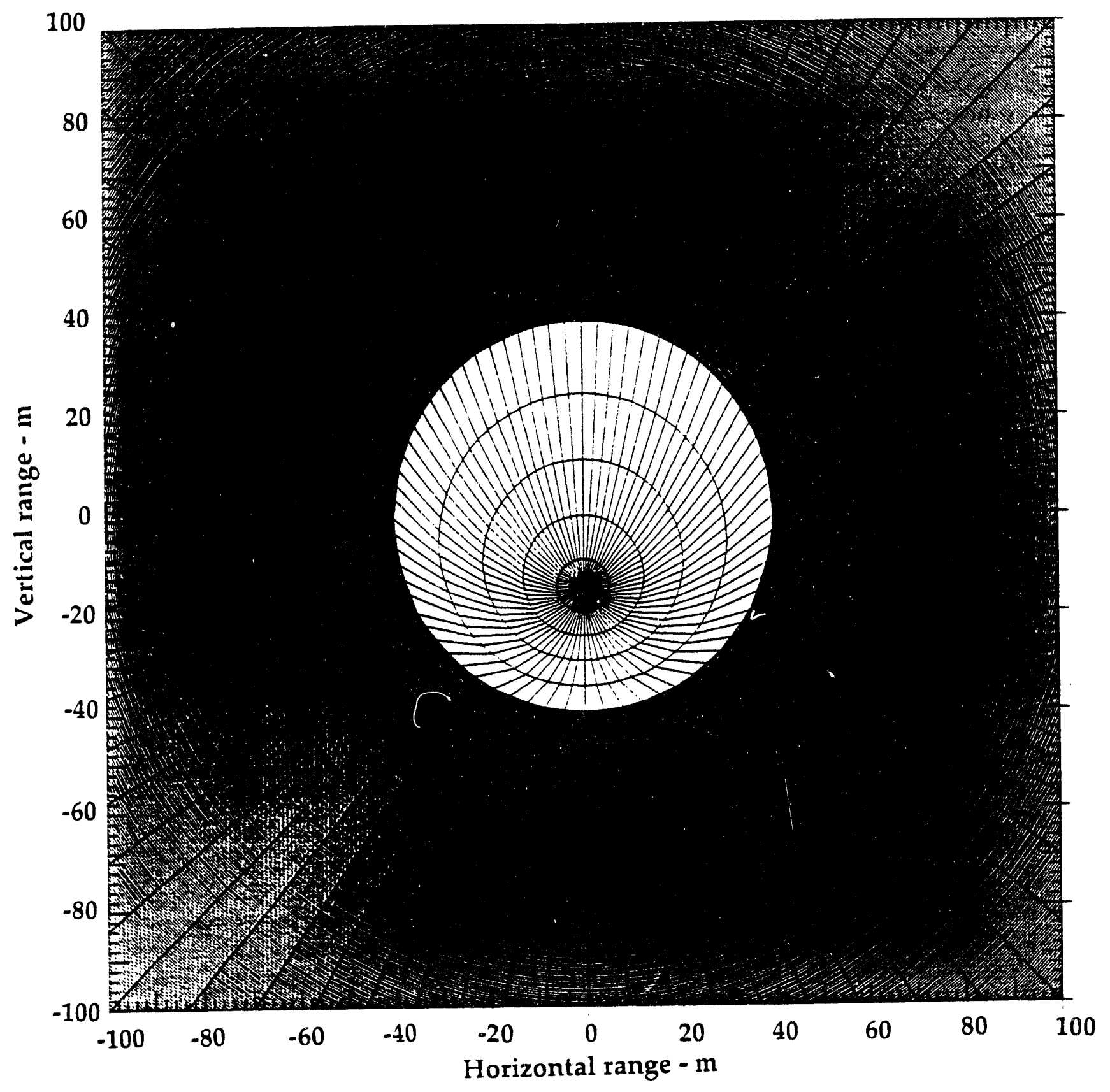

Fig. 6 Snapshot of WIGWAM bubble at $100 \mathrm{msec}$

Center of the bubble is driven downward and oscillates, but the bubble expands spherically. 


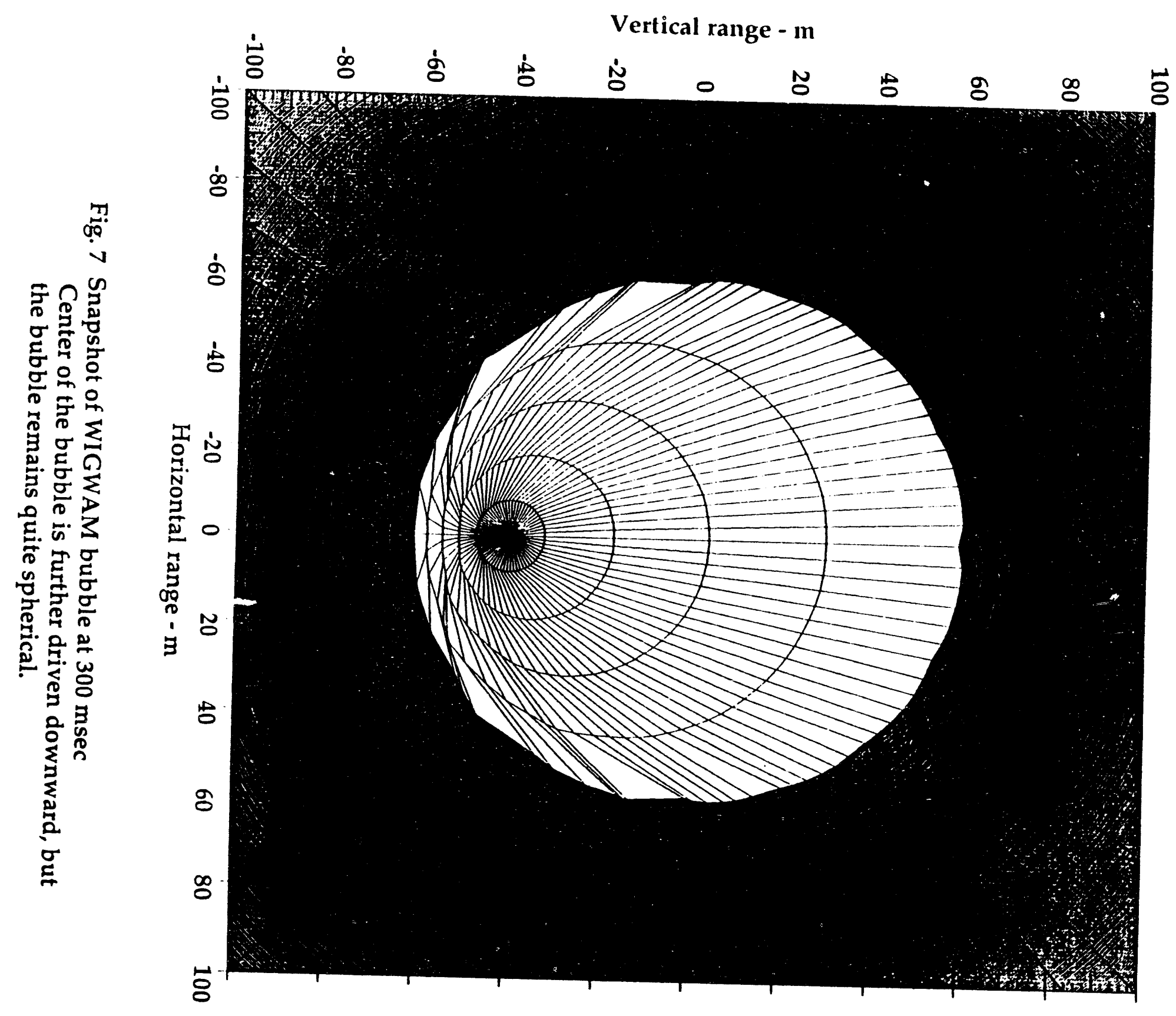



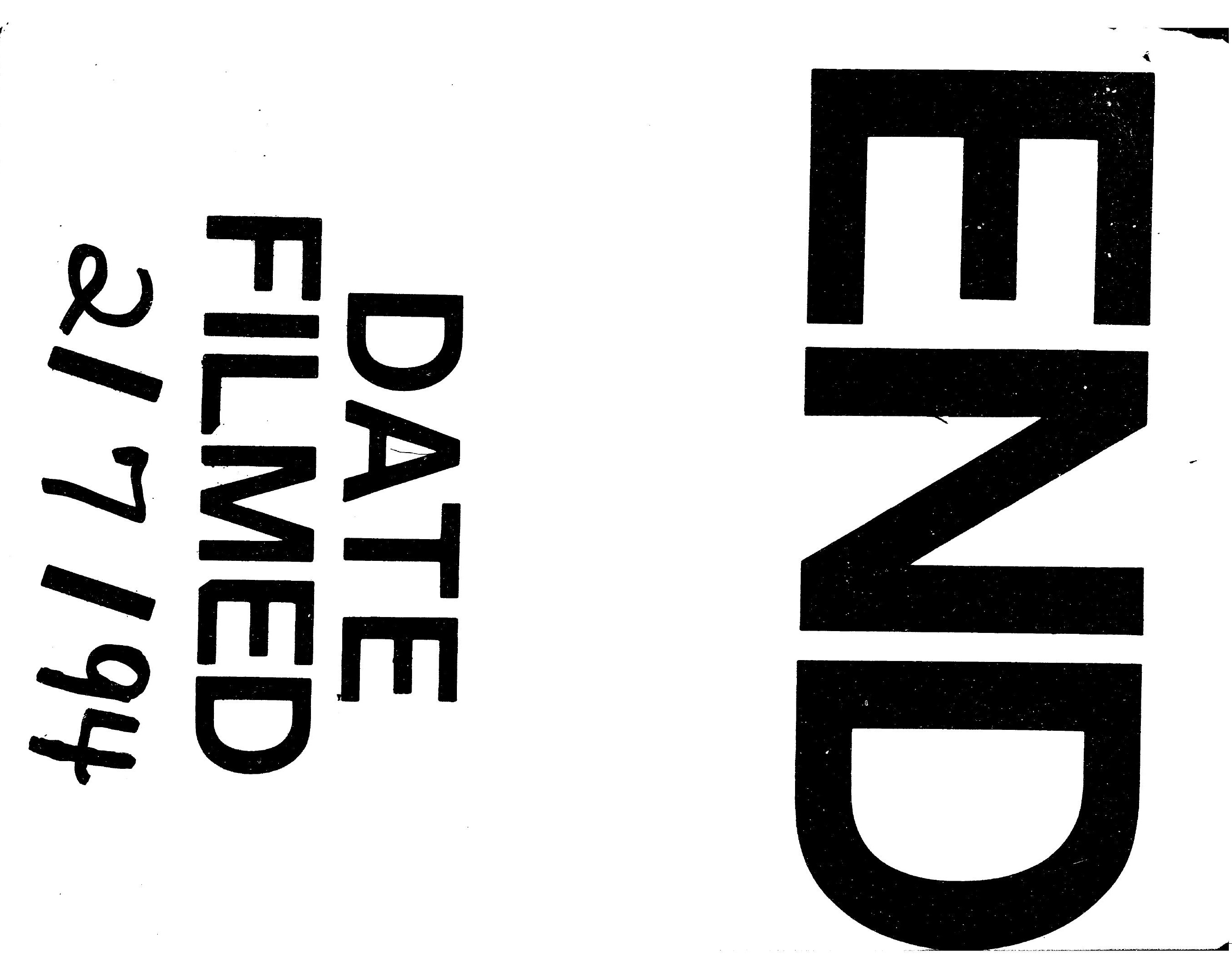
